\title{
CARTA A LOS LECTORES
}

\section{REVISTA HISTORIA DE LA EDUCACIÓN LATINOAMERICANA}

\section{Escuelas en Iberoamérica. Acontecer pedagógico, trasfondo político y maestra rural: prácticas y vida cotidiana en la escuela}

La Revista Historia de la Educación Latinoamericana, edición número dieciocho, trata sobre las Escuelas en Iberoamérica, un tema de importancia que invita a desentrañar los pasados, cruces y nuevos aconteceres en la historia la educación y la pedagogía en los procesos de transformación e inclusión por un orden mundial cada vez más complejo y diverso en su interacción cultural.

Partimos de una simple pregunta ¿A qué concepto de escuelas nos referimos?, a lo que de manera muy rápida podemos responder: al concepto de escuela convergen diversos significados y categorías que conducen a la comprensión de las relaciones educativas, pedagógicas, culturales, ideológico- políticas y del conocimiento, es decir, la escuela es un todo, en la construcción y aprehensión de los saberes y los procesos de socialización.

Conocer las escuelas se constituye en un reto para comprender desde su historia, el presente en el desarrollo de las sociedades rurales, urbanas y étnicas. Las escuelas llevan implícita una concepción educativa que conduce y orientar un tipo de sociedad de hombres y mujeres con sentido cultural y político. Son instituciones que brindan el soporte en la generación de un amplio estilo de relaciones sociales y naturales, y determinan el proyecto de las dinámicas permanentes en los procesos de construcción de nación.

Las escuelas en Iberoamérica, son diversas pero a la vez, una mezcla de pensamiento y posibilidades del antiguo y el nuevo mundo, son también el resultado de los argumentos, discursos y saberes híbridos de culturas interactuantes que se cruzaron en los caminos, pero no por ello, dejaron de ser iguales o disímiles, son simplemente particulares en su contexto. 
Estos contextos hacen referencia a los diversos ámbitos culturales que las acogieron: europeos y americanos (iberoamericanos) rurales y urbanos, aspectos que indican sus similitudes y diferencias.

La escuela consagra desde sus albores un visión ideológico-política, que proyecta una significación clasista y excluyente en su versión euro americana (europeos, criollo y nativos), y posteriormente en la definición campo, ciudad e interculturalidad. En este mismo orden, la escuela levanta sus cimientos sobre objetivos concluyentes: formar buenos ciudadanos, alfabetizar, capacitar para el trabajo y actualmente construir conocimiento para incluirse como ciudadano del mundo. No obstante, la construcción de las escuelas en Iberoamérica tuvo como objetivo central en sus orígenes: sostener el poder de las élites.

Sin duda, con el correr de los tiempos, los requerimientos de las sociedades se van transformando en una búsqueda permanente de conocimientos que les permita comprender la realidad social y natural, transferir y aplicar tecnologías nacientes, consolidar mejores condiciones y estilos de vida, acoplar el orden cultural, político y económico prevaleciente y revisar el ámbito de las relaciones interculturales. Bajo esta perspectiva, las escuelas, aunque tardíamente, deben construir alternativas educativas que les permitan ubicarse de frente al advenimiento de los cambios y transiciones de los procesos sociales y económicos.

Con beneplácito la Revista Historia de la Educación Latinoamericana, en su edición número dieciocho, presenta una versión sobre las Escuelas en Iberoamérica, a través de tres campos que se entrecruzan en su propia dinámica: acontecer pedagógico, trasfondo político y maestra rural, prácticas y vida cotidiana en la escuela.

En el primer campo se presentan cinco artículos que proyectan el acontecer pedagógico de las escuelas en Iberoamérica: Elmys Escribano Hervis, profesor de la Universidad de Ciencias Pedagógicas "Juan Marinello Vidaurreta" de Cuba, presenta el artículo titulado "Nuestra América como plataforma de la educación en el continente". El objetivo de este trabajo es valorar el ensayo "Nuestra América" de José Martí en estrecha relación con el contexto histórico social que lo condicionó y en consonancia con la integralidad de las ideas expuestas por este autor. Afirma Elmys que "Nuestra América convida a hacer causa común con los oprimidos y conceptualiza en el mestizaje, la esencialidad de nuestra cultura".

En otra perspectiva, pero con sentido pedagógico y cultural las autoras y hermanas Alejandrina Lago de Zota, Carmen Lago de Fernández y Diana 
Lago de Vergara, profesoras del Colegio Mayor de Bolívar, Corporación Universitaria Rafael Núñez y Universidad de Cartagena, de la ciudad de Cartagena Colombia, nos dan a conocer su posición crítica a través de su artículo titulado "Educación para ciudadanos del mundo con identidad afrodescendiente: caso Institución Educativa Antonia Santos, Cartagena de Indias, Colombia". En esta investigación las autoras hacen un análisis de las condiciones educativas y sociales de la población afrodescendiente en la ciudad de Cartagena, las políticas educativas estructuradas a partir de la Constitución Política del 1991 y demás normatividad vigentes y la necesidad de proponer alternativas para el currículo, desde los componentes y enfoques que hacen viable una educación intercultural, con identidad afrodescendiente para ciudadanos del mundo.

La brasilera María Helena Camara Bastos de la Pontifícia Universidade Católica do Río Grande do Sul - Brasil, nos presenta la investigación: "Educación Pública e Independencias en las Américas Españolas y Brasil: experiencias lancasterianas en el siglo XIX". Un análisis histórico". Hace referencia a la difusión del método lancasteriano o monitoral/mutuo vinculado a la necesidad de extender la educación a todas las clases sociales, la lucha de la Ilustración y poner en práctica, al menos sobre el papel, los sistemas de educación pública del siglo XIX. Centra su estudio en la experiencia brasileña, haciendo hincapié en su contribución al desarrollo y la generalización de la educación primaria.

La profesora Alba Nidia Triana Ramírez, de la Universidad Pedagógica y Tecnológica de Colombia da cuenta en la investigación sobre la "Formación de maestros rurales colombianos 1946-1994". El artículo trata sobre la evolución de la política y la práctica relacionada con la formación, capacitación y mejoramiento de los maestros rurales en Colombia durante el período comprendido entre 1946 a 1994. Se concluye en este estudio que "la formación de maestros y maestras para la educación rural, no se definió desde los contextos socioculturales, que le permitieran enfrentar la dinámica y compleja vida tradicional campesina, por el contrario, se supeditó a las tendencias de un orden mundial cuya estructura ideológica se fundamentaba en la producción, la globalización y una modernización sin modernidad".

Finaliza este primer campo sobre el acontecer pedagógico de las Escuelas en Iberoamérica con un artículo de la profesora Fanny T. AñañosBedriñana de la Universidad de Granada - España, con una investigación muy importante en el ámbito de la educación social, titulada "Pensamiento y acción socioeducativa en Europa y España. Evolución de la pedagogía y educación social". En este documento la autora desarrolla dos tópicos 
sobre la pedagogía y la educación social: un marco de desarrollo histórico tanto en Europa, especialmente en Alemania, como en España; por otro, un espacio teórico - epistemológico y referencial bajo el amparo de las corrientes actuales de la pedagogía y educación social.

El segundo campo es un trasfondo político, que da cuenta del papel ideológico de la educación y la escuela como estrategia del poder. Este campo se encuentra apoyado por tres investigaciones históricas. Una investigación de la historiadora Flavia Fiorucci de la Universidad Nacional de Quilmes - Argentina: "El campo escolar bajo el peronismo (1946-1955)". Según la autora, el trabajo estudia el impacto de la emergencia del régimen peronista en la vida escolar. Muestra que la escuela fue objeto de reformas y transformaciones importantes en esos años cuya implementación estuvo limitada por un contexto sumamente conflictivo.

El doctor Luis Alarcón Meneses profesor de la Universidad del Atlántico - Colombia, nos permite conocer parte de su trabajo realizado en su año sabático: "Maestros y escuelas Normales en el Caribe colombiano durante el Régimen Federal". Alarcón, en su artículo intenta identificar y analizar algunos de los principales aspectos constitutivos de la cultura escolar propios de las escuelas de la región, lo cual necesariamente implica ocuparse de uno de los principales actores del escenario educativo, como en efecto lo ha sido el maestro, quien conjuntamente con alumnos, padres de familia y funcionarios, entre otros, contribuyó a conformar una cultura escolar.

Un último artículo de trasfondo político es de la historiadora Alina Silveira, profesora de la Universidad de Buenos Aires - Argentina: "Las Escuelas Particulares Inglesas en Buenos Aires (1820-1884)". Afirma la autora, que esta investigación tiene como objetivo indagar sobre el mundo educativo porteño estudiando las escuelas de particulares en manos de ingleses, escoceses, irlandeses, norteamericanos y sus descendientes que se instalaron en la ciudad a partir de 1820 .

Un tercer campo, de vital importancia en la historia de la educación en Iberoamérica está relacionado con la "Maestra rural, prácticas y vida cotidiana en la escuela". Este campo representa el escenario concreto de la realidad educativa. El espacio que articula los sujetos, las prácticas y las instituciones. Bajo esta mirada convergen cinco artículos que referencian la historia, la cotidianidad, las prácticas pedagógicas y el criterio políticoideológico, que surcaron el quehacer de maestras rurales en Iberoamérica, en diferentes periodos. Estos artículos dan cuenta del contexto de la realidad social y cultural a través de historias de vida. En este orden se 
aprecia la investigación de la doctora Diana Soto Arango, profesora de la Universidad Pedagogía y Tecnológica de Colombia coordinadora del Grupo de investigación HISULA -ILAC titulado: "La ruralidad en la cotidianidad escolar colombiana. Historia de vida de la maestra rural boyacense. 19481980". La investigación se centró en el análisis de la historia de vida de una maestra dentro de los contextos de lo rural y lo urbano atravesados por un período histórico de violencia en Colombia, en los años de 1948 que va transformándose con el denominado Frente Nacional, (1958-1974), en la región cundi-boyacense.

Seguidamente, encontramos un artículo de la doctora María Cristina Vera de Flachs CONICET- Universidad Nacional de Córdoba - Argentina, el título de este importante trabajo se denomina: "Rosario Vera Peñaloza una maestra que dejó huella en la historia de la educación de la Argentina". La autora expresa que el objetivo de este trabajo fue repensar la vida y obra de Rosario Vera Peñaloza, una maestra normalista que a lo largo de su existencia ha sido sin duda un referente en el proceso educativo argentino.

La profesora Gabriela Hernándę de la Universidad de Nariño Colombia, nos presenta una historia que pretende evidenciar la acción pedagógica que realizaron tres maestras a finales del siglo XIX en las ciudades de Pasto, Ipiales y Túquerres, ubicadas en la región sur del país. El trabajo de estas maestras se desarrolló durante los últimos años del gobierno liberal radical e inicios de la regeneración, razón por la cual, tanto las instituciones educativas como las maestras tuvieron que convivir con las tensiones políticas de la época.

El profesor José Edimar de Souza de La Fundação Escola Técnica Liberato Salzano Vieira da Cunha - Brasil, presenta un estudio que gira en torno a los hechos y las reflexiones sobre la enseñanza de la historia de una maestra de escuela primaria, cuya carrera se ha desarrollado en las zonas rurales de Novo Hamburgo/RS entre 1940 y 1960. Especifica el objetivo de esta investigación, a partir de la reflexión sobre la enseñanza en diferentes localidades de la zona rural de Lomba Grande, atravesada por una maestra - Gersy - en el desarrollo de su enseñanza, se centra en su historia tejida en las clases de multigrado.

Cada una de las investigaciones expuestas en esta revista, son una invitación a la reflexión sobre la historia de la educación. Pero a la vez, presentan elementos para la construcción de un pensamiento crítico y recreativo a cerca del devenir ideológico, político, cultural, pedagógico y económico de los pueblos en Iberoamérica. 
Finalmente, agradecemos a los investigadores que aportaron sus trabajos a esta significativa producción académica, que como siempre caracteriza positivamente a la revista Historia de la Educación Latinoamericana. De la misma manera resaltar el criterio científico que la doctora Diana Elvira Soto Arango le imprime a esta loable labor intelectual, y como siempre una especial gratitud al acompañamiento del comité científico y comité científico internacional, pués gracias a este grupo de investigadores es posible alcanzar la calidad de la publicación de esta revista. Una vez más, agradecer el entusiasmo y trabajo propuesto por Mgs. Sandra Liliana Bernal Villate, ya que sin su apoyo cotidiano no sería posible lograr una edición más.

\author{
Alba Nidia Triana Ramírez \\ Co-editora RHELA No. 18. \\ Universidad Pedagógica y Tecnológica de Colombia
}

